\title{
Virtual microscopy beyond the pyramids, applications of WSI in Cairo University for E-education \& telepathology
}

\author{
Essam Ayad ${ }^{\mathrm{a}, *}$ and Yukako Yagi ${ }^{\mathrm{b}}$ \\ ${ }^{a}$ Digital Pathology Unit, Cairo University, Cairo, Egypt \\ ${ }^{\mathrm{b}}$ MGH Pathology Imaging and Communication Technology (PICT) Center, Massachusetts General Hospital, \\ Boston, MA, USA
}

\begin{abstract}
Background: Telepathology, the practice of pathology at a long distance, has advanced continuously since 1986. The progress of telepathology passed through four stages: Static, Dynamic, Hybrid \& Whole Slide Imaging.

Materials and methods: A pilot project between the Italian Hospital in Cairo \& the Civico Hospital in Palermo was completed successfully, applying the static \& dynamic techniques of telepathology. This project began in 2003 and continued till now. In 2004, centers in Venice, London and Pittsburgh participated actively in our project.

Results: Over eight years we consulted on many problematic pathological cases with specialized pathological centers in Italy, UK \& USA. In addition to the highly specialized scientific value, we saved a lot of time and money.

Conclusion: We concluded from our experience that telepathology is a very useful and applicable tool for additional consulting on difficult pathological cases especially for emerging countries. In view of this success we have already established our Digital Telepathology Unit in Cairo University, using the WSI technique in teaching which was greatly successful and encouraged us to build a huge digital pathology library which will expand our telepathology \& E-learning programs to cover staff and students in Egypt and Eastern Mediterranean.
\end{abstract}

Keywords: Telepathology, Egypt, Cairo University, Italy, UCDMC, WSI, E-learning

\section{Background}

Telepathology is the practice of pathology at a distance, viewing images on a monitor rather than directly through a light microscope. In today's health care system, there are many uses of telepathology. For example, to "provide urgent services at sites either without a pathologist or sites with a pathologist requiring additional professional backup". Also, telepathology can "provide immediate access to sub-specialty pathol-

${ }^{*}$ Corresponding author: Essam Ayad, Department of Pathology, Faculty of Medicine, Cairo University, Cairo, Egypt. Tel.: +2 010 6690 370; Fax: +2 0233356 470; E-mail: essamayad@yahoo.com. ogy consultants". In general, telepathology techniques are classified into Static, Dynamic, Hybrid and Whole Slide Imaging (WSI).

\section{Materials and methods}

We have two successful experiences in Egypt in the application of the telepathology; the first was using the static and dynamic techniques of telepathology through a pilot project between the Italian Hospital in Cairo (NPO) (Fig. 1) and Civico Hospital in Palermo.

This project began in 2003 by initiating the idea of the cooperation between CIVICO hospital in Palermo 


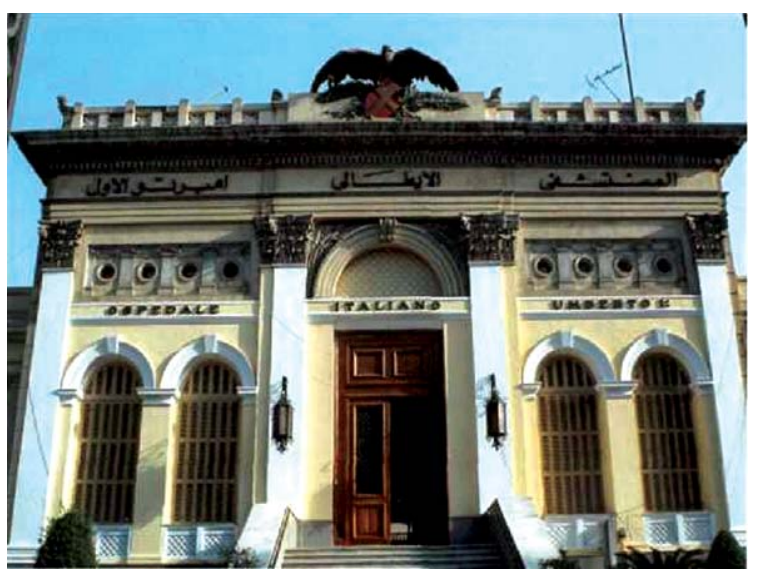

Fig. 1. Italian hospital in Cairo.

and the Italian hospital in Cairo, followed by the signing of a protocol of cooperation between both hospitals. The project is divided into four phases: Telepathology, Teleechocardiography, Tele-radiology \& Tele-Endoscopy. The first phase (Telepathology) is now practically mature. The next phases of our project will be: Tele-echocardiography, Tele-radiology $\&$ Tele-endoscopy. For the first phase (Telepathology), these steps were taken: evaluation of the costs and securing the required funding; searching for the best instruments in the Egyptian market with the required functionality and certifications: downloading, and using in Cairo, the same software as used in Palermo; and the beginning of the connection. In addition during the second year 2004, (Ospedale S. Giovanni e Paolo Hospital in Venice, Charing Cross Hospital in London and University of Pittsburgh Medical Center Health System (UPMC) in USA joined as active participants in the telepathology project. The essential needs for our complete telepathology unit were straightforward: a suitable place, a server with a high-speed internet connection, a full computer system (computer, scanner \& printer, a binocular microscope, a digital camera for gross pathology, a digital camera connected to the microscope to capture images from the microscope, a video-camera connected to the computer for video-conferences and suitable software for image processing and image transfer via the internet The benefits we expected and have achieved from the introduction of this telepathology unit are clear: better medical service, more distributed specialization, savings in time and money, increased knowledge exchange provides strong basis for improved teaching and learn- ing practices. This unit has also provided its services to any pathology department in the Egyptian universities or any research centre.

The success of the first project encouraged us to begin the second project which is establishing a new digital pathology unit in the pathology department, Cairo University (Fig. 2) using the WSI technique (Fig. 3).

This unit began work two years ago. During the passed two years we established a digital pathology library for the under graduate students using the WSI technique and changed the teaching method of the histopathology slides to be completely digital. We are building another digital pathology library for post graduate candidates that will be available to all pathology candidates in Egyptian universities \& universities in the surrounding Arabic countries. We are also creating a digital pathology network between pathology centers in the Middle East for exchanging knowledge \& telepathology. Moreover we began a new collaboration with UCDMC Department of Pathology, Sacramento in the field of telepathology to exchange experiences $\&$ teleconsultation.

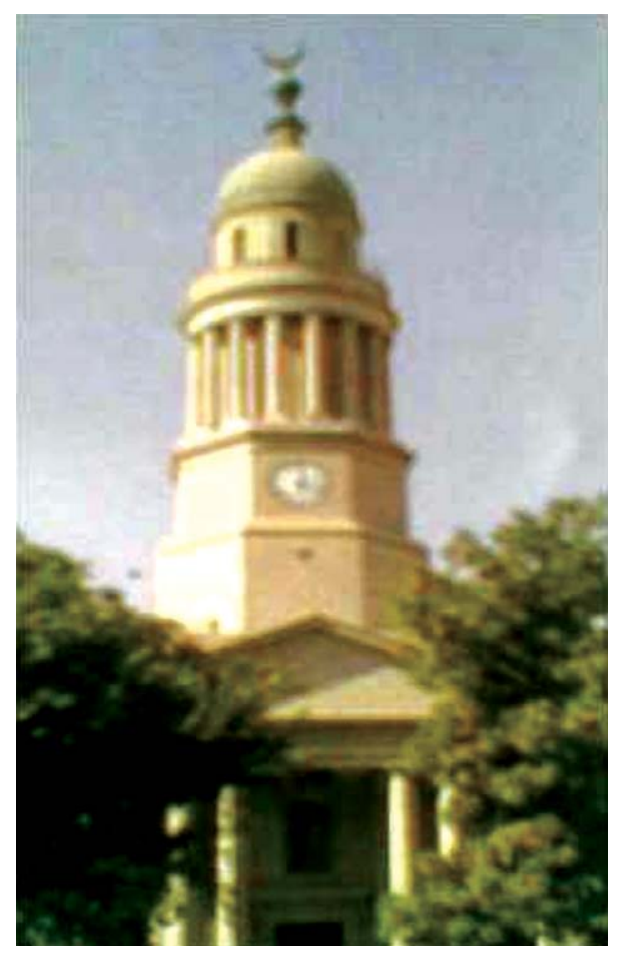

Fig. 2. Faculty of Medicine. 


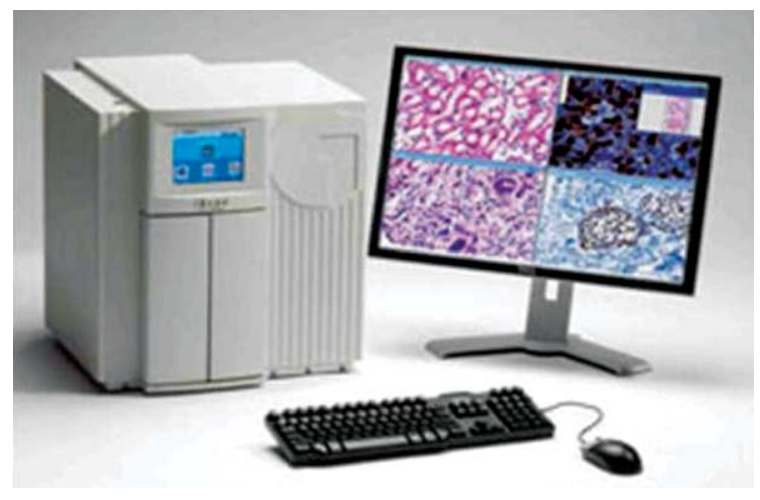

Fig. 3. WSI unit, Cairo University.

\section{Results}

Over the past 5 years (from 2003-2008) we consulted 250 problematic pathological cases (50 cases/year) with these different specialized pathological centers in Italy, UK \& USA. Beside the highly specialized scientific value of consulting the cases and exchanging knowledge, we saved a lot of time and more than 75.000 US\$ moreover offering our patients a better medical service. Despite of these promising results, we faced a lot of disadvantages of both static \& dynamic methods of telepathology like the bad image quality \& lack of its standardization methods, the big image file size, the limitation of the area selection (which depends on the experience of the sending pathologists), the low image quality at receiver site (which depends on the bandwidth of network used) and lastly we found that the robotic dynamic telepathology program was not so common.

So In view of the success of our project and to avoid the disadvantages of the static \& dynamic methods of telepathology, we established our Digital Telepathology Unit (DTU) in the pathology department, Cairo University using the WSI technology. Even during the passed short period since the beginning of our digital pathology WSI unit, we changed the teaching method for the under graduate medical students to be completely digital which was markedly successful and widely accepted by the medical students. Using WSI technique in teaching also increased the acceptance of the entire staff member to use digitalized slides even in the routine examination of cases \& telepathology. We also began scanning most of our valuable pathology slides to create a new digital pathology library for post graduate candidates that will be available to all pathology candidates in Egyptian universities \& universities in the surrounding Arabic countries. We also began communication with pathology centers in the all Arabic countries within the Middle East to create a digital pathology network between for exchanging knowledge \& telepathology. We are also trying to complete the pilot phase of our new collaboration with UCDMC Department of Pathology, Sacramento to begin the next steps in accepting these channels as documented tool in diagnosis \& teleconsultation.

\section{Conclusion}

We concluded from our experience that telepathology is a very useful and applicable tool for additional consulting on difficult pathological cases especially for emerging countries. It has significantly increased knowledge exchange and thereby ensured our patients a better medical service, while simultaneously saving a lot of time and money over the previous practice. In view of this success we established our Digital Telepathology Unit (DTU) in the pathology department, Cairo University. The application of WSI technique in teaching was greatly successful and encouraged us to create a huge digital pathology library which will expand our telepathology \& E-learning programs to cover our staff and students both in Egypt and in the longer term in the wider Eastern Mediterranean.

\section{References}

[1] F. Sicurello, E. Ayad, S. Corrao and G. Marino, Interhospital teleconsulting project between Cairo and Palermo Nuove Tecnologie in Medicina, Applicazioni Informatiche Etelematiche in Medicina Anno 4 (2004), 4-7.

[2] Y. Yagi and J.R. Gilbertson, Digital imaging in pathology: the case for standardization, J Telemed Telecare 11(3) (2005), 109-116.

[3] J. Ho, A.V. Parwani, D.M. Jukic, Y. Yagi, L. Anthony and J.R. Gilbertson, Use of whole slide imaging in surgical pathology quality assurance: Design and pilot validation studies, Hum Pathol 37(3) (2006), 331-322.

[4] J.R. Gilbertson, J. Ho, L. Anthony, D.M. Jukic, Y. Yagi and A.V. Parwani, Primary histologic diagnosis using automated whole slide imaging: A validation study, BMC Clin Pathol, Apr 27; 6 (2006), 4. Publish with BioMed Central and every scientist can read your work free of charge.

[5] R.S. Weinstein, A.R. Graham, L.C. Richter, G.P. Barker, E.A. Krupinski, A.M. Lopez, K.A. Erps, A.K. Bhattacharyya, Y. Yagi and J.R. Gilbertson, Overview of telepathology, virtual microscopy, and whole slide imaging: Prospects for the future, Hum Pathol 40(8) (2009), 1057-1069. Epub 2009 Jun 24 Aug. 


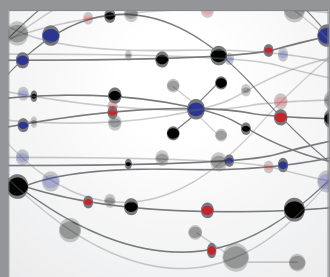

The Scientific World Journal
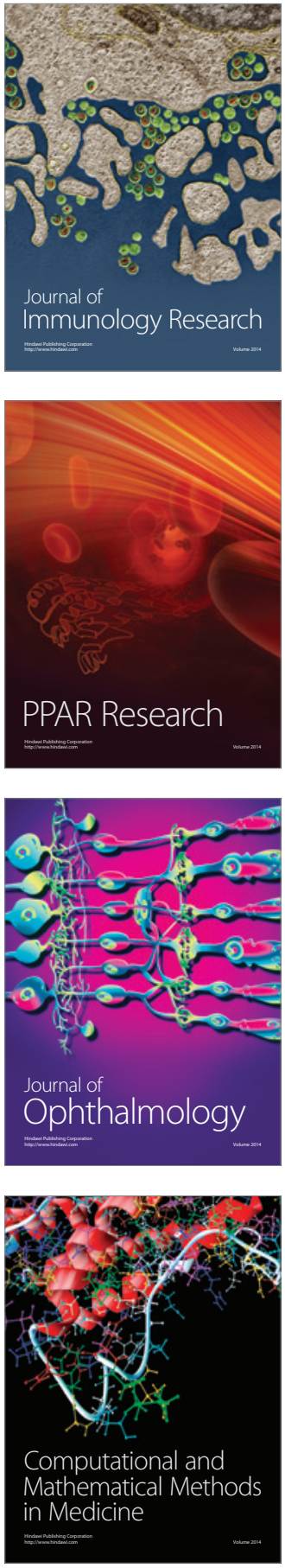

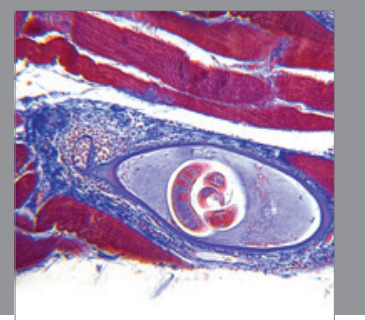

Gastroenterology

Research and Practice
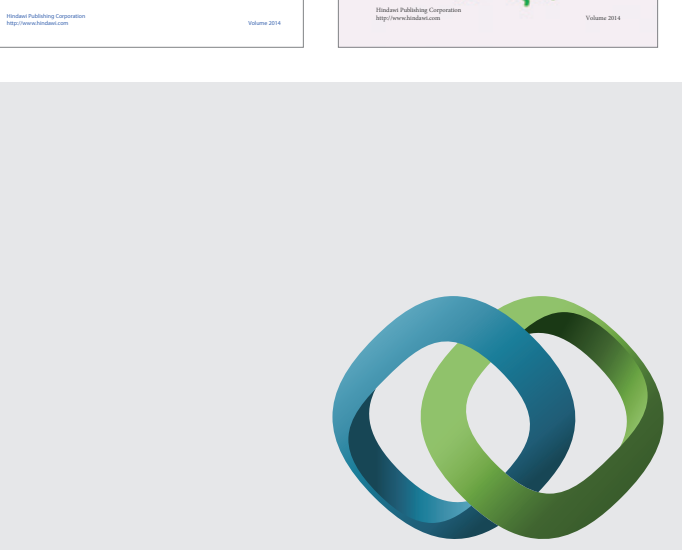

\section{Hindawi}

Submit your manuscripts at

http://www.hindawi.com
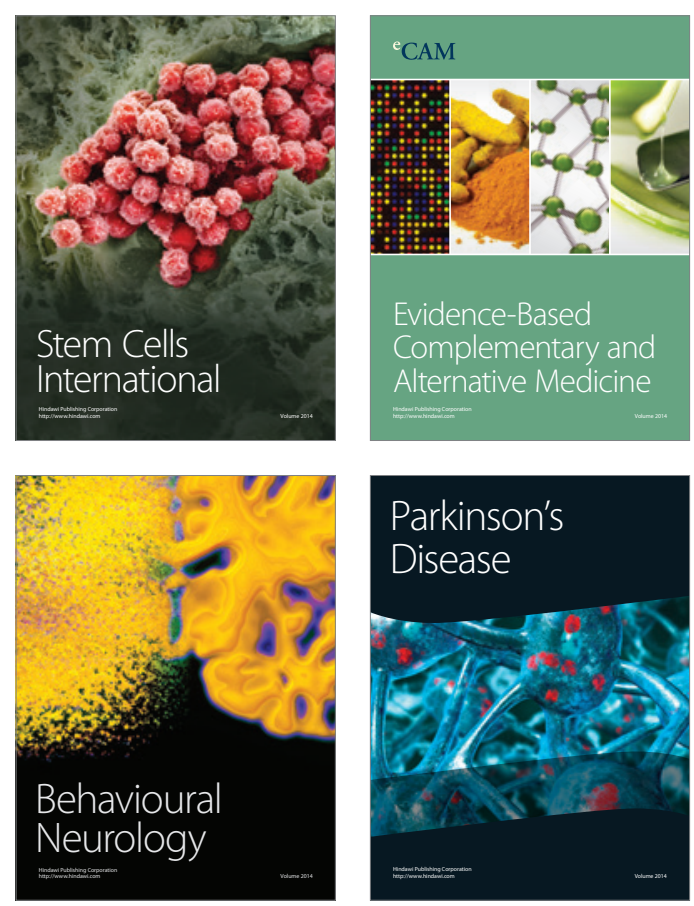

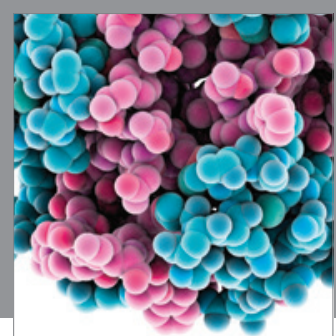

Journal of
Diabetes Research

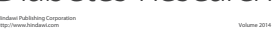

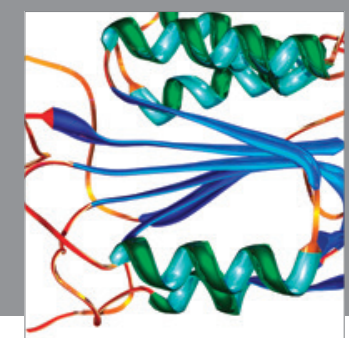

Disease Markers
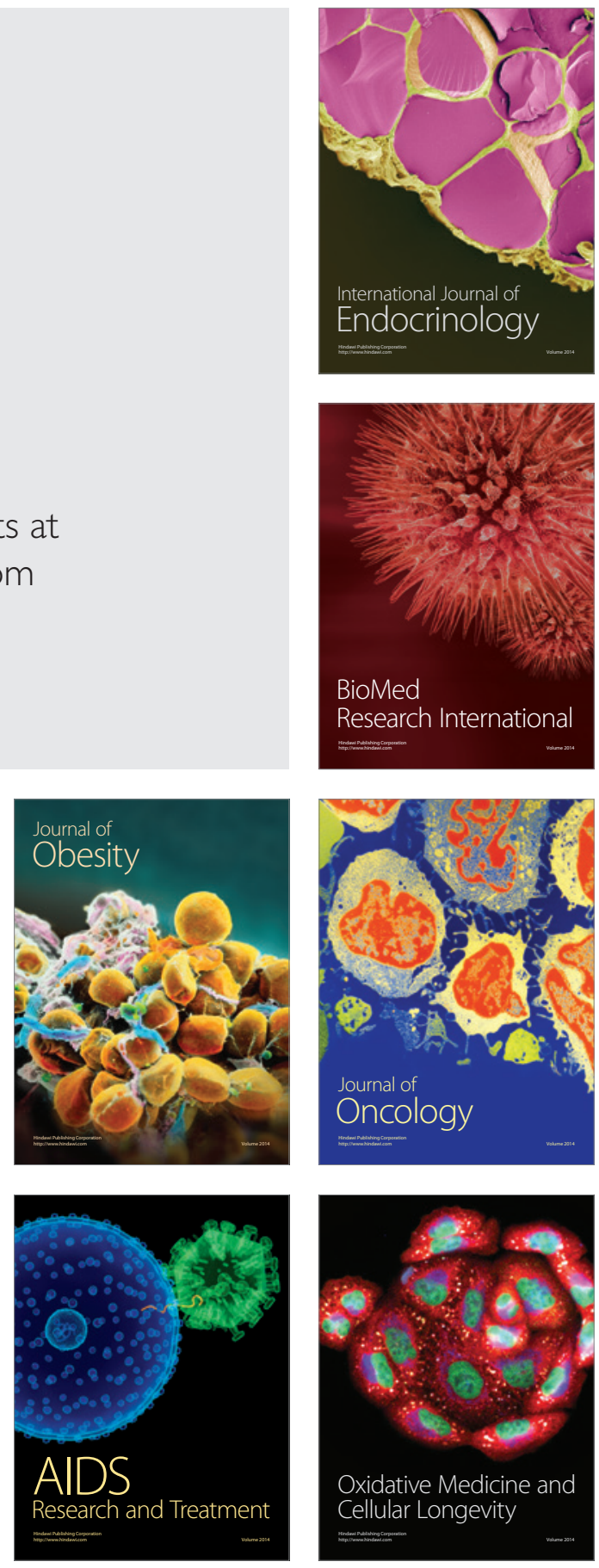